\title{
Undercorrection of hypernatremia is frequent and associated with mortality
}

\author{
Stanislas Bataille ${ }^{1 *+}$, Camille Baralla ${ }^{2 \dagger}$, Dominique Torro ${ }^{2}$, Christophe Buffat ${ }^{3}$, Yvon Berland ${ }^{1}$, Marc Alazia ${ }^{2}$, \\ Anderson Loundou ${ }^{4}$, Pierre Michelet ${ }^{2}$ and Henri Vacher-Coponat ${ }^{1}$
}

\begin{abstract}
Background: About 1\% of patients admitted to the Emergency Department (ED) have hypernatremia, a condition associated with a mortality rate of 20 to $60 \%$. Management recommendations originate from intensive care unit studies, in which patients and medical diseases differ from those in ED.

Methods: We retrospectively studied clinical characteristics, treatments, and outcomes of severely hypernatremic patients in the ED and risk factors associated with death occurrence during hospitalization.

Results: During 2010, 85 cases of severe hypernatremia $\geq 150 \mathrm{mmol} / \mathrm{l}$ were admitted to ED. Hypernatremia occurred in frail patients: mean age 79.7 years, 55\% institutionalized, 28\% with dementia.

Twenty four percent of patients died during hospitalization. Male gender and low mean blood pressure (MBP) were independently associated with death, as well as slow natremia correction speed, but not the severity of hyperosmolarity at admission. Infusion solute was inappropriate for $45 \%$ of patients with MBP $<70 \mathrm{mmHg}$ who received hypotonic solutes and $22 \%$ of patients with $\mathrm{MBP} \geq 70 \mathrm{mmHg}$ who received isotonic solutes or were not perfused.

Conclusions: This is the first study assessing outcome of hypernatremic patients in the ED according to the treatment provided. It appears that not only a too quick, but also a too slow correction speed is associated with an increased risk of death regardless of initial natremia. Medical management of hypernatremic patients must be improved regarding evaluation and treatment.
\end{abstract}

Keywords: Intracellular dehydration, Dysnatremia, Hypernatremia, Renal failure, Emergency, Mortality

\section{Background}

Hypernatremia is diagnosed in 1 to $2 \%$ of patients admitted to the Emergency Department (ED). Such patients often have various underlying pathologies implicated in hypernatremia occurrence [1]. In most cases, treatment of hypernatremia is started at ED, but there have been only two reports on the characteristics, symptoms, treatments, and outcomes of severely hypernatremic patients at ED $[1,2]$.

The recommended hypernatremia correction speed, based on pediatric retrospective case-series [2], is $1 \mathrm{mmol} / \mathrm{L} / \mathrm{h}$ when hypernatremia occurrence has been quick ( $\mathrm{a}$ few hours) and $0.5 \mathrm{mmol} / \mathrm{L} / \mathrm{h}$ when it has been long or is

\footnotetext{
* Correspondence: stanislas.bataille@ap-hm.fr

${ }^{+}$Equal contributors

'Aix-Marseille University, APHM, Hôpital de la Conception, Centre de néphrologie et transplantation rénale, Marseille 13005, France

Full list of author information is available at the end of the article
}

unknown [3-6]. A too fast correction can induce cerebral edema and irreversible neurologic sequels that are avoided with a slow correction [3,5,7]. Unless shock or hypotension are present, isotonic or hypertonic solutes are not recommended. Moreover, experts recommend first replacing fluid losses in dehydrated/hypovolemic patients by use of isotonic or slightly hypotonic fluids (e.g. lactated Ringer's) [8].

To avoid over- or under-treatment, which both might cause neurological complications (cerebral edema, seizure, or coma), management of intravenous fluid must be rationalized. Mathematic calculation of water deficit based on sodium and water distribution in the intraand extra-cellular spaces has been proposed. This requires two clinical data: natremia measurement and patient weight. For example, Adrogue and Madias's formula serves to calculate natremia variation after perfusion of

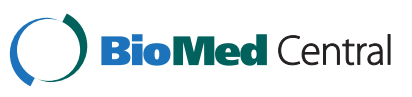


one liter of solute according to the type of solute, initial natremia, and total body water volume: Attended natremia $=([\mathrm{Na}]$ of solute - initial natremia $) /($ Total body water volume - 1) $[3,9,10]$. Most formulas consider the human body as a closed system and do not integrate undergoing losses of water. Furthermore, total body water volume required for calculation is extrapolated from weight regardless of the percentage of body fat variability. Also, these formulas were found to be imprecise in individual patients with deviations $>10 \mathrm{mmol} / \mathrm{L}$ [11]. Their inappropriate use might lead to hypernatremia under-correction or worsening [12].

Mortality of hypernatremic patients reaches $20 \%$ to $60 \%[2,12-15]$ and varies according to comorbidities, associated illness, and whether hypernatremia is present at admission or acquired during hospitalization $[2,16]$. Hypernatremia at admission or acquired during the hospitalization is an independent mortality risk factor [2,15-17].

In this study, we report clinical characteristics, management, outcome and mortality risk factors of severely hypernatremic patients admitted to the ED.

\section{Methods}

We retrospectively studied all patients admitted between January 2010 and January 2011 to the main adult ED of the center of Marseille, France. Each day an average of 150 patients are admitted. The medical team was constituted at daytime of 4 senior doctors and 5 residents and at night 3 senior doctors and 5 residents.

Patients were identified using the computerized registry of the biochemistry lab. All patients with natremia $\geq 150 \mathrm{mmol} / \mathrm{L}$ at admission were included in the study. Data collected from medical files were age, gender, place of origin and personal environment (home, institution or home medical care), cause of admission, blood pressure, presence of extracellular dehydration signs (decreased skin turgor, lower limb edema, hypotonic ocular globes), presence of neurologic symptoms (disorientation, agitation, somnolence, coma), medical history of dementia, usual treatments, sequential serum sodium measured during the hospitalization, creatinine at admission, ED main diagnosis, and patient outcome in ED and during the following hospitalization. We also collected composition and perfusion rate of prescribed intravenous perfusions. Speed of natremia correction was calculated using available natremia on the first day, the third day, and the last known natremia (i.e., natremia at death, normalization, or loss to follow-up). Patients with no natremia improvement between entry and the last known natremia were defined as the no natremia improvement group. The plasma tonicity and osmolarity were calculated using the classical formulas: tonicity $=([\mathrm{Na}]+[\mathrm{K}]) \times 2+$ Glycemia; osmolarity $=([\mathrm{Na}]+[\mathrm{K}]) \times 2+$ Urea + Glycemia .
Estimated glomerular filtration rate (eGFR) was calculated using the MDRD formula [17].

Hypotension requiring isotonic solute perfusion was defined as a mean blood pressure (MBP) $<70 \mathrm{mmHg}$. Optimal correction rate of hypernatremia was defined as a decreasing rate between 0.5 to $1 \mathrm{mmol} / \mathrm{L} / \mathrm{h}$ with a maximum of $12 \mathrm{mmol} / \mathrm{L} /$ day [3-6].

Statistical analysis was performed using SPSS version 1.0 and Stata 12. Continuous variables were expressed as means $\pm \mathrm{SD}$ or as median with range ( $\min , \max )$, and categorical variables were reported as count and/or percentages. A Cox regression analysis was conducted to identify mortality risk factors. A p-value of $<0.10$ in the univariate analysis was chosen to define the variables to be entered into the selection procedure for the multivariable model. A step by step backward procedure was used to identify variables with a p-value $<0.05$ in the multivariate model. Natremia at admission was included in the multivariate model as an adjustment variable. Hazard ratios were expressed with 95\% confidence intervals. All the tests were two-sided. Data with more than four groups were clustered to define correct Hazard Ratios. Research was conducted according to standard recommendations of the local ethics committee (Comite de Protection des Personnes Sud-Méditerranée II - www. cpp-sudmed2.fr) and followed the standards of the Helsinki Declaration. As defined by the French Public Health Code (Articles L1121-1 and R1121-2), no institutional review board and no written informed consent is required for "research in which all practices and products are used in the usual way, without any additional or unusual procedure for diagnosis or monitoring", thus, for retrospective studies.

\section{Results}

Between January 2010 and January 2011, 54753 admissions were recorded in our ED, 16351 (29.8\%) of them had a serum sodium dosing. Hypernatremia $>145 \mathrm{mmol} / \mathrm{L}$ was found in 226 admissions, i.e., $0.4 \%$ of admissions and $1.4 \%$ of admissions with natremia dosing.

Within the 226 hypernatremic admissions, 141 were between 146 and $149 \mathrm{mmol} / \mathrm{L}$ and not included in this study. The 85 admissions (82 patients) with severe hypernatremia, i.e., $\geq 150 \mathrm{mmol} / \mathrm{L}(0.2 \%$ of admissions and $0.5 \%$ of admissions with natremia dosing), were included in this study.

The main characteristics of these 85 admissions are reported in Table 1. At admission, mean natremia was $158 \pm 8 \mathrm{mmol} / \mathrm{L}$. For $68 \%$ of patients natremia was between 150 and $160 \mathrm{mmol} / \mathrm{L}$ and for 32\% between 161 and $187 \mathrm{mmol} / \mathrm{L}$ (Figure 1A). Mean calculated plasmatic tonicity was $347 \pm 25 \mathrm{mOsm} / \mathrm{L}$, and mean calculated plasmatic osmolarity was $356 \pm 26 \mathrm{mOsm} / \mathrm{L}$. A urinary ionogram was performed for only 3 patients. 
Table 1 Characteristics of hypernatremic patients and risk factors for death occurrence during hospitalization

Characteristics

Age (years)

Male

Cause of admission
Total population Death during hospitalization No death during hospitalization

$(\%$ or mean $\pm S D) \quad(\%$ or mean $\pm S D)$

$\mathrm{n}=\mathbf{8 5}$

$79.7 \pm 14$

$44 \%$

$85.3 \pm 10.7$

$63 \%$

(\% or mean \pm SD)

$\mathbf{n}=\mathbf{5 9}$

$77.2 \pm 14.7$

$41 \%$

Asthenia

$40 \%$

$53 \%$

$32 \%$

Short breath

$16 \%$

$12 \%$

$32 \%$

$5 \%$

$6 \%$

Fever

$9 \%$

$0 \%$

$15 \%$

Diarrhea, vomiting or abdominal pain

$8 \%$

$0 \%$

$14 \%$

Neurologic symptom

Trauma

$4 \%$

Hypotension

Gastrointestinal bleeding

$4 \%$

$2 \%$

Other

Place of origin and personal environment

Home
Institution
Home medical care

$$
45 \%
$$

$50 \%$

$5 \%$

Season of occurrence

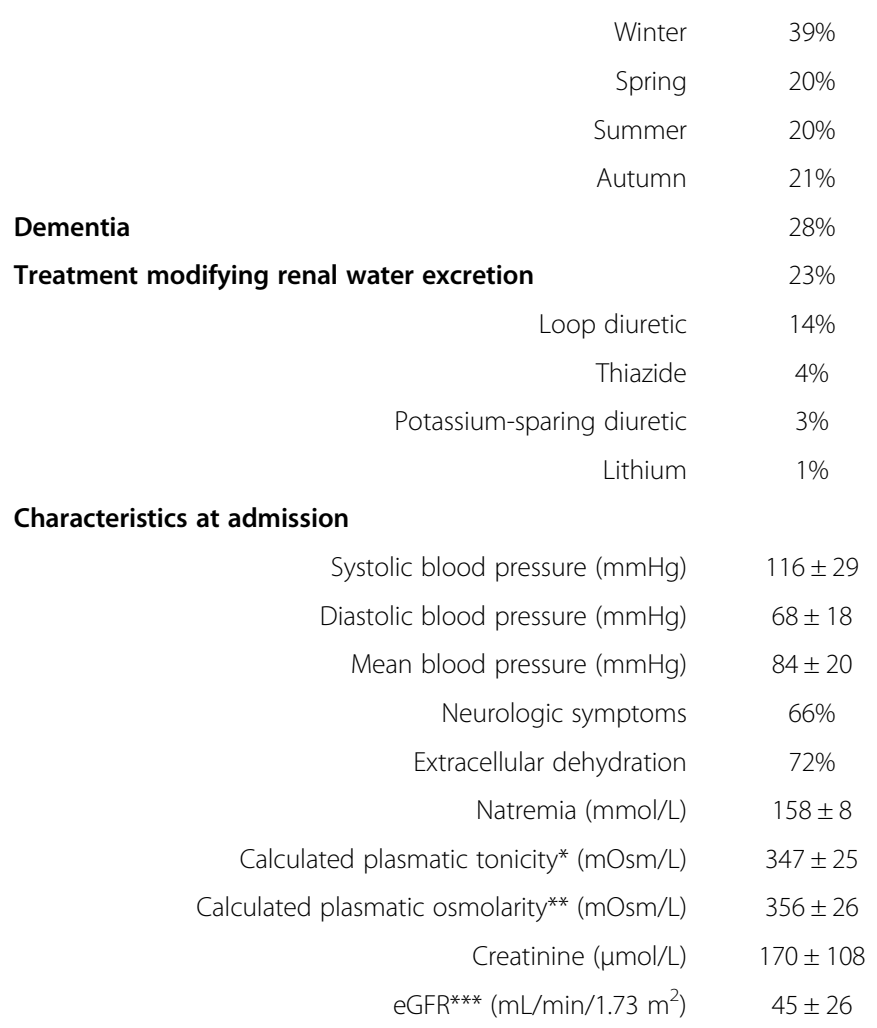

Main diagnosis in emergency department

$$
42 \%
$$$$
47 \%
$$$$
11 \%
$$

$46 \%$

$3 \%$

$34 \%$

$24 \%$

$20 \%$

$22 \%$

$27 \%$

$24 \%$

$14 \%$

$$
4 \%
$$

$4 \%$

$2 \%$

$0 \%$

$$
\begin{gathered}
122 \pm 26 \\
73 \pm 17 \\
89.6 \pm 17.8 \\
59 \% \\
67 \% \\
158.5 \pm 8.3 \\
346 \pm 24 \\
355 \pm 25 \\
152 \pm 95 \\
48.9 \pm 26.4
\end{gathered}
$$$$
55 \pm 15
$$$$
67.8 \pm 15.0
$$$$
88 \%
$$

$\begin{array}{cc}158.2 \pm 6.5 & 158.5 \pm 8.3 \\ 357 \pm 28 & 346 \pm 24 \\ 365 \pm 29 & 355 \pm 25 \\ 225 \pm 117 & 152 \pm 95 \\ 33.6 \pm 24.2 & 48.9 \pm 26.4\end{array}$


Table 1 Characteristics of hypernatremic patients and risk factors for death occurrence during hospitalization (Continued)

\begin{tabular}{|c|c|c|c|}
\hline Shock (septic $n=3$, hypovolemic $n=1$ ) & $5 \%$ & $40 \%$ & $16 \%$ \\
\hline Acute pulmonary edema & $2 \%$ & $2 \%$ & $0 \%$ \\
\hline Other & $13 \%$ & $9 \%$ & $16 \%$ \\
\hline \multicolumn{4}{|l|}{ Perfused solute } \\
\hline Hypotonic solute & $64 \%$ & $53 \%$ & $65 \%$ \\
\hline Isotonic solute & $28 \%$ & $42 \%$ & $23 \%$ \\
\hline No perfusion & $1 \%$ & $0 \%$ & $2 \%$ \\
\hline Unknown & $7 \%$ & $5 \%$ & $11 \%$ \\
\hline \multicolumn{4}{|l|}{ Natremia correction speed: } \\
\hline $\begin{array}{l}\text { Mean speed between entry and last known natremia } \\
\qquad(\mathrm{mmol} / \mathrm{L} / \mathrm{h})\end{array}$ & $-0.18 \pm 0.21$ & $-0.1 \pm 0.15$ & $-0.2 \pm 0.22$ \\
\hline No natremia improvement & $27 \%$ & $44 \%$ & $21 \%$ \\
\hline
\end{tabular}

Seven patients who were lost to follow-up on the day of admission were not included in statistical analysis. ${ }^{*}$ Calculated plasmatic tonicity $=([\mathrm{Na}]+[\mathrm{K}]) \times 2+$ Glycemia. ${ }^{* *}$ Calculated plasmatic osmolarity $=([\mathrm{Na}]+[\mathrm{K}]) \times 2+$ Urea + Glycemia. ${ }^{* * *}$ Glomerular filtration rate (eGFR) was estimated with the simplified Modification of Diet in Renal Diseases formula [23].

Mean creatinine at admission was $170 \pm 108 \mu \mathrm{mol} / \mathrm{L}$, but no information was available with regard to acute or chronic renal failure. Using the MDRD formula, which is appropriate for chronic renal failure, mean eGFR was $45 \pm$ $26 \mathrm{~mL} / \mathrm{min} / 1.73 \mathrm{~m}^{2} ; 94 \%$ of patients had an eGFR $<90 \mathrm{~mL} /$ $\min / 1.73 \mathrm{~m}^{2}, 69 \%$ an eGFR $<60 \mathrm{~mL} / \mathrm{min} / 1.73 \mathrm{~m}^{2}$, and $34 \%$ an eGFR $<30 \mathrm{~mL} / \mathrm{min} / 1.73 \mathrm{~m}^{2}$ (Figure $1 \mathrm{~B}$ ).

For $47 \%$ of patients, main diagnosis recorded at the ED was a medical disease frequently associated with water loss: infection (pulmonary $\mathrm{n}=20$, urinary $\mathrm{n}=11$, other $n=4$ ), gastrointestinal disease (diverticulitis $n=1$, diarrhea $n=2$, gastroenteritis $n=2$ ) (Table 1$)$.

Surprisingly, hypernatremia was more frequent in winter (39\% of cases) than in spring (20\%), autumn (21\%), and notably summer (20\%). In summer, a short peak was observed in July, the hottest month of 2010 in Marseille (Figure 1C).

Rehydration treatment prescribed at ED is reported in Table 2. Intravenous perfusions was inappropriate for $45 \%$ of patients with $\mathrm{MBP}<70 \mathrm{mmHg}$ who received a hypotonic solute, and for $22 \%$ with $\mathrm{MBP} \geq 70 \mathrm{mmHg}$ who received isotonic solute or were not perfused. In $74 \%$ of the medical files perfusion speed was missing; in $6 \%$ the perfusion setting by the nurse was not reported.

After their ED evaluation, 78 of the 85 patients (92\%) were hospitalized (Figure 1A, Table 3), 5 returned to their previous institution, 1 died in the $\mathrm{ED}$, and 1 patient's outcome is unknown. Mean hospitalization duration was $13.1 \pm 13$ days.

Natremia evolutions and patient outcomes are reported in Table 3. Compared to admission, natremia on the next day was worse in $34 \%$, identical in $8 \%$, and improved in $58 \%$ of patients. For $65 \%$ of patients with improvement, correction was $<0.5 \mathrm{mmol} / \mathrm{L} / \mathrm{h}$, for $32 \%$ between 0.5 and $1 \mathrm{mmol} / \mathrm{L} / \mathrm{h}$, and $>1 \mathrm{mmol} / \mathrm{L} / \mathrm{h}$ for 1 patient who did not die during hospitalization. Overall, only $19 \%$ of patients improved their natremia with the recommended rate of 0.5 to $1 \mathrm{mmol} / \mathrm{L} / \mathrm{h}$.

During hospitalization, $57 \%$ of patients normalized their natremia. Their mean rate of lowering was $-0.24 \pm$ $0.2 \mathrm{mmol} / \mathrm{L} / \mathrm{h}$ in $4.87 \pm 3.28$ days (from 11 hours to 14 days). Among them, 39\% had normal natremia on the third day and $80 \%$ on the $7^{\text {th }}$ day. When leaving the hospital, $27 \%$ of patients had no natremia improvement and $19 \%$ had not normalized their natremia.

Hospital mortality rate was $24 \%$ (19 patients), occurring $5.8 \pm 7$ days after their arrival in ED, $47 \%$ patients died on the first two days (including the patient who died in ED); $68 \%$ in the first week; and $32 \%$ after 7 days of hospitalization. Last natremia before death was $155 \pm 9 \mathrm{mmol} / \mathrm{L}$, with a lowering speed of $-0.1 \pm 0.15 \mathrm{mmol} / \mathrm{L} / \mathrm{h}$. Only $11 \%$ of patients had natremia normalized before death.

Because perfusion speed was unknown in $74 \%$ of the cohort, we were not able to analyze the link between perfusion speed and natremia correction speed. Taking this limit into account, the type of solute prescribed was not associated with the correction speed during the first day (hypotonic solute $-0.2 \pm 0.37 \mathrm{mmol} / \mathrm{L} / \mathrm{h}$ versus $-0.21 \pm$ $0.44 \mathrm{mmol} / \mathrm{L} / \mathrm{h}$ with isotonic solute, $\mathrm{p}=0.98$ ).

In monovariate analysis, risk factors at admission for in-hospital death were (Table 4) older age $(\mathrm{p}=0.04)$, presence of neurologic symptoms $(p=0.03)$, lower systolic blood pressure $(\mathrm{p}<0.001)$, lower diastolic blood pressure $(p=0.001)$, lower MBP $(p<0.001)$, higher creatinine $(\mathrm{p}=0.004)$, lower eGFR $(\mathrm{p}=0.03)$, infection as the main diagnosis in the ED ( $\mathrm{p}=0.004)$, and having no natremia improvement $(\mathrm{p}=0.02)$.

In multivariate analysis, male gender $(\mathrm{p}=0.007 ; \mathrm{HR}=$ 5.65 95\% CI [1.60-19.90]), lower MBP $\left(\mathrm{p}<10^{-3} ; \mathrm{HR}=0.92\right.$ 95\% CI [0.88-0.95]), and slow mean correction speed to 


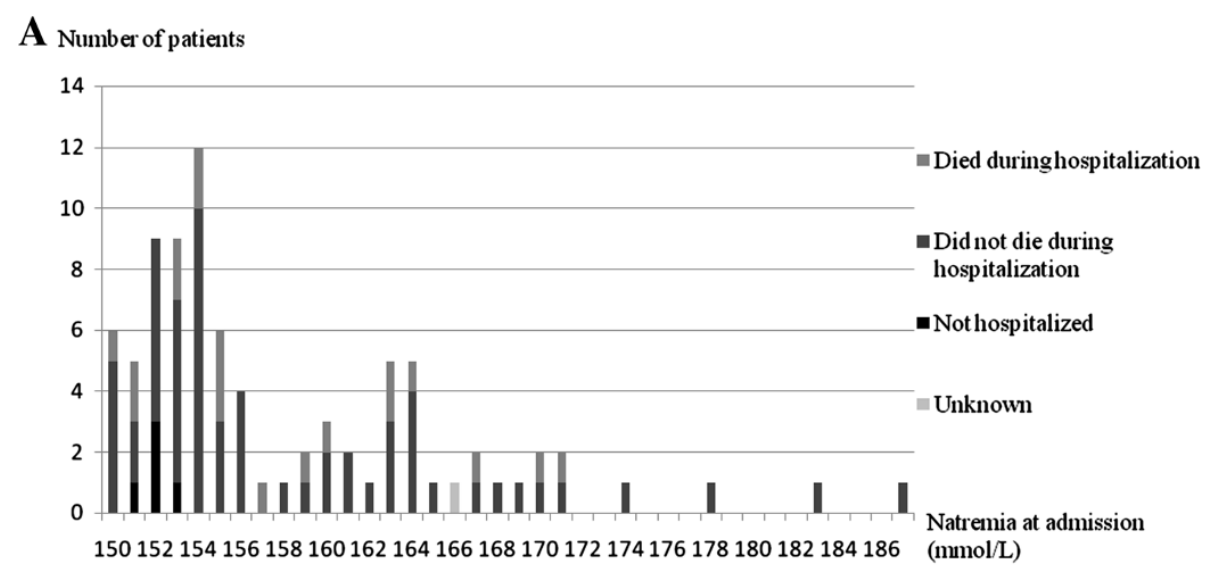

B Number of patients

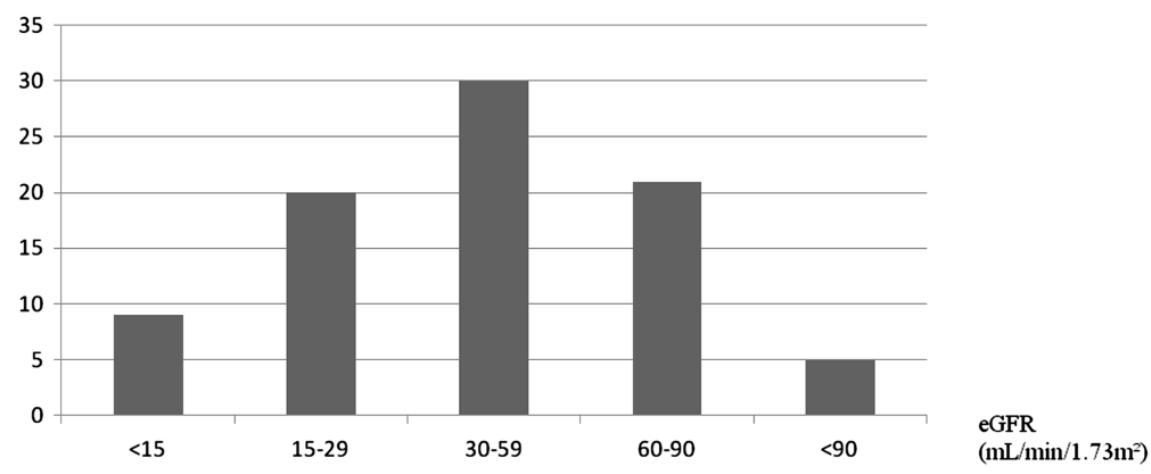

C

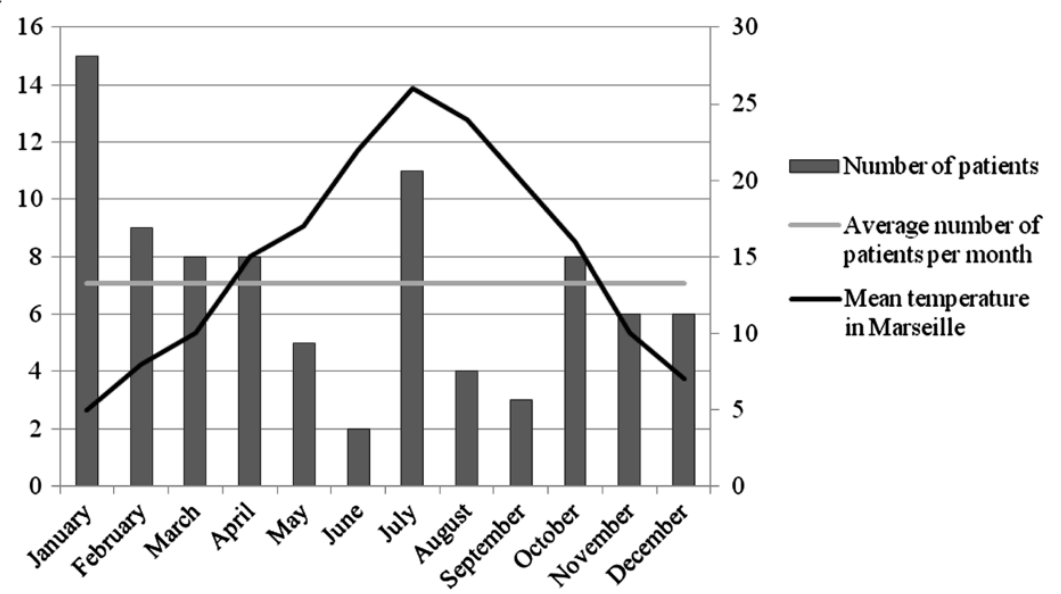

Figure 1 Clinical and biological features of hypernatremic patients. A. Natremia at admission and outcomes of hypernatremic patients. B. Renal function at admission. Renal function at admission was measured using estimated glomerular filtration rate (eGFR) estimated by Modification of Diet in Renal Disease formula (23). C. Month of occurrence of hypernatremia.

last known natremia ( $\mathrm{p}<10^{-3}$; $\mathrm{HR}=10.29$ 95\% CI [3.1233.96]) were associated with death occurrence during hospitalization.

\section{Discussion}

Our study describes initial presentation, management, and outcomes of severely hypernatremic patients $(\geq 150 \mathrm{mmol} / \mathrm{L})$ in the ED and during the following hospitalization. Relative to the 50000 patients hospitalized each year in our ED, severe hypernatremia is a rare event. However, unlike in-hospital acquired hypernatremia, most patients with hypernatremia at hospital admission receive initial treatment in the ED. To our knowledge, very few studies have reported on presentation, management and outcome 
Table 2 Initial fluid replacement strategy on arrival at emergency department

\begin{tabular}{|c|c|}
\hline Treatments & $\mathrm{n}=85$ \\
\hline \multicolumn{2}{|l|}{ Perfused solute } \\
\hline Hypotonic solute & $64 \%$ \\
\hline Isotonic solute & $28 \%$ \\
\hline $0.9 \%$ sodium chloride & $67 \%$ \\
\hline Ringer's lactate* & $21 \%$ \\
\hline Hydroxyethyl starch $130 / 0.4^{* *}$ & $12 \%$ \\
\hline No perfusion & $1 \%$ \\
\hline Unknown & $7 \%$ \\
\hline \multicolumn{2}{|c|}{ Perfused solute according to mean blood pressure } \\
\hline $\mathrm{MBP}<70 \mathrm{mmHg}$ & $24 \%$ \\
\hline Hypotonic solute & $45 \%$ \\
\hline Isotonic solute & $55 \%$ \\
\hline $\mathrm{MBP} \geq 70 \mathrm{mmHg}$ & $69 \%$ \\
\hline Hypotonic solute & $71 \%$ \\
\hline Isotonic solute & $20 \%$ \\
\hline No perfusion & $2 \%$ \\
\hline Unknown & $7 \%$ \\
\hline Unknown MBP & $7 \%$ \\
\hline \multicolumn{2}{|l|}{ Other } \\
\hline No prescribed perfusion rate & $74 \%$ \\
\hline Perfusion not reported in file by the nurse & $6 \%$ \\
\hline \multicolumn{2}{|c|}{$\begin{array}{l}\text { *Ringer's lactate contains sodium lactate } 3.2 \mathrm{~g} / \mathrm{L} \text { and sodium chloride } 6 \mathrm{~g} / \mathrm{L} \text {. } \\
\text { **Hydroxyethyl starch } 130 / 0.4 \text { contains hydroxyethyl starch } 13060 \mathrm{~g} / \mathrm{L} \text { and } \\
\text { sodium chloride } 9 \mathrm{~g} / \mathrm{L} \text {. } \\
\text { As described in the Methods, hypotension requiring isotonic solute perfusion } \\
\text { was defined as a mean blood pressure (MBP) }<70 \mathrm{mmHg} \text {. Thus, intravenous } \\
\text { perfusion was inappropriate for almost half of patients with } \mathrm{MBP}<70 \mathrm{mmHG} \\
\text { who received hypotonic solutes, and for nearly a quarter when } \mathrm{MBP} \geq 70 \mathrm{mmHg} \\
\text { who received isotonic solutes or were not perfused. }\end{array}$} \\
\hline
\end{tabular}

of severely hypernatremic patients upon their arrival to the hospital (Table 5) $[1,2,18]$. Arampatzis et al. reported hypernatremia $>145 \mathrm{mmol} / \mathrm{L}$ in $0.9 \%$ of patients admitted toED and $1.5 \%$ of patients with natremia dosing, and severe hypernatremia $\geq 150 \mathrm{mmol} / \mathrm{L}$ in $0.1 \%$ of admissions and $0.2 \%$ of patients with natremia dosing, which is similar to our results.

In our study, hypernatremic patients were old (mean age 79.7 years-old), lived in medical institutions or at home with medical care (55\%), and had cognitive impairment (28\% had dementia), which are situations of thirst impairment and/or limited access to water and at high risk for dehydration [19-21]. Moreover, for $47 \%$ of patients with severe hypernatremia $\geq 150 \mathrm{mmol} / \mathrm{l}$, the main diagnosis was a situation associated with water loss, and $23 \%$ of patients had a treatment modifying renal water excretion.

Hot weather is an understandable risk factor for hypernatremia, and summer heat is regularly evoked
Table 3 Outcome and natremia evolution in the emergency department and during hospitalization

\begin{tabular}{|c|c|}
\hline Outcome & $\mathrm{n}=85$ \\
\hline \multicolumn{2}{|l|}{ All patients } \\
\hline \multicolumn{2}{|l|}{ Outcome after emergency department } \\
\hline Hospitalization & $92 \%$ \\
\hline Back to institution & $6 \%$ \\
\hline Died at emergency department & $1 \%$ \\
\hline Unknown & $1 \%$ \\
\hline In hospital mortality & $24 \%$ \\
\hline Mean time to death (days) & $5.8 \pm 6$ \\
\hline Hospitalized patients & $\mathrm{n}=78$ \\
\hline Natremia at admission (mmol/L) & $158 \pm 8$ \\
\hline \multicolumn{2}{|l|}{ On the next day $(n=59)$} \\
\hline $\begin{array}{l}\text { Time lag between initial natremia and next } \\
\text { day natremia }\end{array}$ & 17 h21 \pm 6 h28 \\
\hline Mean natremia (mmol/L) & $156 \pm 7$ \\
\hline Mean correction speed (mmol/L/h) & $-0.18 \pm 0.39$ \\
\hline Worsened natremia & $34 \%$ \\
\hline Same natremia as at admission & $8 \%$ \\
\hline Improved natremia & $58 \%$ \\
\hline At a less than $0.5 \mathrm{mmol} / \mathrm{L} / \mathrm{h}$ speed & $65 \%$ \\
\hline At a 0.5 to $1 \mathrm{mmol} / \mathrm{L} / \mathrm{h}$ speed & $32 \%$ \\
\hline At a more than $1 \mathrm{mmol} / \mathrm{L} / \mathrm{h}$ speed & $3 \%$ \\
\hline
\end{tabular}

On the third day $(n=53)$

Time lag between initial natremia and $3^{\text {rd }}$ day natremia (days)

$2,47 \pm 0.72$

Mean natremia $(\mathrm{mmol} / \mathrm{L})$

$150 \pm 8$

Mean correction speed (mmol/L/h)

$-0.15 \pm 0.19$

Worsened natremia

$11 \%$

Same natremia as at admission

$6 \%$

Improved but not normalized natremia

$51 \%$

Normalized natremia

$32 \%$

Mean hospitalization time (days)

$13.1 \pm 13$

Data are given as mean \pm standard deviation or percentages.

[20]. Surprisingly, in our study, hypernatremia was more frequent in winter. Several hypotheses can be proposed: less important care given to patient's hydration in winter than in summer [22], a higher infection rate in winter [23]. A peak of hypernatremia was also noted in July, the hottest month in our city in 2010 and the $6^{\text {th }}$ hottest July since 1900 with a temperature $1.9^{\circ} \mathrm{C}$ above normal (Source Météo France, http://climat.meteofrance.com). Clearly, heat is an important risk factor for hypernatremia, but our study also highlights that an adequate water intake in the elderly is important all year.

Neurological symptoms are frequent in hypernatremia, and we report that $66 \%$ of patients had at least one neurological symptom at admission. This is higher than 
Table 4 Factors associated with death during hospitalization: univariate and multivariate analysis using a Cox regression model $(n=78)$

\begin{tabular}{|c|c|c|c|c|c|c|}
\hline & \multicolumn{3}{|c|}{ Monovariate analysis } & \multicolumn{3}{|c|}{ Multivariate analysis } \\
\hline & $p$ & HR & $\mathrm{Cl} 95 \%$ & $\mathbf{p}$ & Adjusted HR & $\mathrm{Cl} 95 \%$ \\
\hline Age & 0.04 & 1.05 & $1.00-1.10$ & & & \\
\hline Male gender & 0.06 & 2.47 & $0.97-6.28$ & 0.007 & 5.65 & $1.60-19.90$ \\
\hline \multicolumn{7}{|l|}{ Place of origin and personal environment: } \\
\hline Home & Ref. & Ref. & Ref. & & & \\
\hline Institution or home medical care & 0.65 & 1.24 & $0.50-3.08$ & & & \\
\hline \multicolumn{7}{|l|}{ Season of occurrence: } \\
\hline Winter & Ref. & Ref. & Ref. & & & \\
\hline Spring & 0.36 & 0.54 & $0.15-2.00$ & & & \\
\hline Summer & 0.79 & 0.86 & $0.29-2.59$ & & & \\
\hline Autumn & 0.21 & 0.38 & $0.08-1.75$ & & & \\
\hline Dementia & 0.54 & 1.40 & $0.48-4.04$ & & & \\
\hline Treatment modifying renal water excretion & 0.95 & 1.04 & $0.32-3.33$ & & & \\
\hline \multicolumn{7}{|l|}{ Characteristics at admission: } \\
\hline Systolic blood pressure $(\mathrm{mmHg}) \dagger$ & $<0.001$ & 0.97 & $0.95-0.98$ & & & \\
\hline Diastolic blood pressure $(\mathrm{mmHg}) \dagger$ & 0.001 & 0.95 & $0.92-0.98$ & & & \\
\hline Mean blood pressure & $<0.001$ & 0.95 & $0.92-0.97$ & $<0.001$ & 0.92 & $0.91-1.06$ \\
\hline Neurologic symptoms & 0.03 & 5.22 & $1.20-22.78$ & & & \\
\hline Extracellular dehydration & 0.07 & 4.02 & $0.92-17.63$ & & & \\
\hline Natremia (mmol/L) & 0.88 & 1.01 & $0.94-1.07$ & 0.64 & 0.98 & $0.88-0.95$ \\
\hline Calculated plasmatic tonicity $(\mathrm{mOsm} / \mathrm{L}) \dagger$ & 0.06 & 1.02 & $1.00-1.04$ & & & \\
\hline Calculated plasmatic osmolarity (mOsm/L) & 0.09 & 1.02 & $1.00-1.03$ & & & \\
\hline Creatinine $(\mu \mathrm{mol} / \mathrm{L})$ & 0.004 & 1.01 & $1.00-1.01$ & & & \\
\hline $\operatorname{eGFR}\left(\mathrm{mL} / \mathrm{min} / 1.73 \mathrm{~m}^{2}\right) \dagger$ & 0.03 & 0.98 & $0.95-1.00$ & & & \\
\hline \multicolumn{7}{|l|}{ Main diagnosis in emergency department: } \\
\hline Extracellular dehydration & Ref. & Ref. & Ref. & & & \\
\hline Infection & 0.04 & 4.21 & $1.09-16.29$ & & & \\
\hline \multicolumn{7}{|l|}{ Other } \\
\hline Perfused solute: & 0.18 & 2.46 & $0.67-9.10$ & & & \\
\hline Hypotonic solute & Ref. & Ref. & Ref. & & & \\
\hline Isotonic solute, no perfusion or unknown & 0.44 & 1.43 & $0.58-3.52$ & & & \\
\hline \multicolumn{7}{|l|}{ Natremia correction speed: } \\
\hline Mean speed between entry and last known natremia $(\mathrm{mmol} / \mathrm{L} / \mathrm{h}) \dagger$ & 0.10 & 18.79 & $0.59-597.13$ & & & \\
\hline No natremia improvement & 0.02 & 3.12 & $1.22-7.96$ & $<0.001$ & 10.29 & $3.12-33.96$ \\
\hline
\end{tabular}

Factors indicated by + were not included in the multivariate analysis because a linked factor was already included in the analysis.

the $38 \%$ reported by Arampatzis et al., who do not specify how many patients had previous dementia [2]. Extracellular dehydration was present in most patients (72\%) and could be responsible for the hypotension and the renal impairment observed in 69\% of patients (eGFR below $60 \mathrm{~mL} / \mathrm{min} / 1.73 \mathrm{~m}^{2}$ ).

This is the first study analyzing natremia correction speed and treatment given to hypernatremic patients in ED. We show that under-correction is frequent in the
ED and in the first few days following admission: on the day after admission, $42 \%$ had a worsened or identical natremia; and on the third day following admission, natremia was normalized in only $32 \%$ of patients. More than one patient out of four had no natremia improvement between entry and last follow-up. Overcorrection is rare and only one patient with lithium induced nephrogenic insipid diabetes had a correction speed $>1$ $\mathrm{mmol} / \mathrm{L} / \mathrm{h}$. He had a good evolution and returned to 
Table 5 Studies reporting out-of-hospital acquired hypernatremia

\begin{tabular}{|c|c|c|c|c|}
\hline & Liamis et al. [15] & Arampatzis et al. [1] & Arampatzis et al. [2] & Baralla et al. \\
\hline Publication year & 2008 & 2012 & 2012 & 2013 \\
\hline Country & Greece & Switzerland & Switzerland & France \\
\hline Department & Internal medicine & Emergency & Emergency & Emergency \\
\hline Hypernatremia definition (mmol/L) & $>148$ & $>142$ & $\geq 150$ & $\geq 150$ \\
\hline$N=$ & 55 & 400 & 74 & 85 \\
\hline Mean age (years) & $76.3 \pm 12.2$ & $53 \pm 22$ & NA & $79.7 \pm 14$ \\
\hline Males & $40 \%$ & $59 \%$ & $62 \%$ & $44 \%$ \\
\hline Mean Na (mmol/L) & $160.4 \pm 9.9$ & $144 \pm 2$ & 152 & $158 \pm 8$ \\
\hline Mortality during hospitalization & $28 \%$ & NA & $28 \%$ & $24 \%$ \\
\hline
\end{tabular}

Arampatzis et al. published two studies in the same year. Patients of the second study with hypernatremia defined as $\geq 150 \mathrm{mmol} / \mathrm{L}$ were a subgroup of the former larger study, with an unclassical hypernatremia definition.

his institution after hospitalization. Optimal speed of natremia correction is not clearly established but experts agree that the correction speed should not exceed $1 \mathrm{mmol} / \mathrm{L} / \mathrm{h}$, without a given lower limit [3-6]. Nevertheless, it is important not to prolong hypernatremia duration which induces cerebral suffering and the risk of neurological sequels, decreases cardiac contractility, increases peripheral insulin resistance and impairs hepatic neoglucogenesis [24]. We could not determine whether insufficient correction of hypernatremia was due to a low speed of perfusion because perfusion speed was missing in $74 \%$ of the cohort. This high percentage of missing data might reflect the lack of precision of medical prescriptions or the lack of transcription of the nurse on the medical file. Moreover, this speed must be adjusted to total body water deficit extrapolated from natremia and body weight, but weight was recorded for only 3 patients. Also, water loss was evaluated from urinary ionogram in only 3 patients. Besides the too slow perfusion speed, mistakes in the type of solute chosen for rehydration could at least partly explain under-correction, as $22 \%$ of patients with $\mathrm{MBP} \geq 70 \mathrm{mmHg}$ either received isotonic solute or were not perfused.

Despite the non classical management of hypernatremia, the mortality rate of our cohort $(24 \%)$ is similar to those previously reported, suggesting that our practices are comparable to those of other EDs (Table 5). In intensive care units, hypernatremia occurrence is a known mortality risk factor but patients are different and hypernatremia is frequently iatrogenic [24]. Indeed, the consequences of cerebral edema differ with age, with a major risk at younger age when the size ratio of brain to cranial volume is high [25]. In our study, hypernatremic patients were old and often had dementia, two conditions associated with cerebral atrophy. Moreover, we show that hypovolemia signs (extracellular dehydration, hypotension, and renal insufficiency) are the principal risk factors for death during hospitalization, suggesting that associated illness and medical status are the major risk factors for death in patients with hypernatremia acquired outside the hospital. This hypothesis is supported by the short delay before death $(68 \%$ in the first week, most of them during the first 2 days). Three of the 4 patients with a diagnosis of shock at ED died during hospitalization.

In this study, we did not find a statistical link between the level of hypernatremia and mortality. Higher calculated plasmatic tonicity and calculated plasmatic osmolarity were associated with death in the monovariate model (Table 4), but not in the multivariate analysis. The 85 cases analyzed represent a relatively small cohort and there were numerous confounding factors such as loss to follow-up, associated comorbidities, and associated acute illness. The small cohort size also probably explains why the relationship between hypernatremia and death did not reach statistical significance. Moreover, our monocentric study might reflect local practices and a local effect. Nevertheless, in our study, a too slow natremia correction speed was associated with death. This is the first study reporting that under-correction of hypernatremia is associated with an increased mortality. Time spent with intracellular dehydration could be more important than the severity of hypernatremia or hyperosmolarity. In hyponatremia, it is well known that a too high correction speed can lead to osmotic demyelination. In hypernatremia, similar recommendations are given, but physicians should also be aware that a too slow correction rate could increase the risk of death.

\section{Conclusion}

This is the first study assessing outcome of hypernatremic patients in an ED according to the provided treatment. It suggests that medical management of hypernatremic patients must be improved regarding evaluation (weight, diuresis, urinary ionogram) and management (type of solute, perfusion speed) and that a too slow correction speed is associated with an increased risk of death regardless of initial natremia. 


\section{Competing interests}

The authors declare that they have no competing interests.

\section{Authors' contributions}

SB and CBa collected and analyzed the data and wrote the paper. DT had the idea and supervised the study. CBu provided the biological data. YB, MA and PM gave advice to improve the study. AL did the statistical analysis. HVC supervised the study and guided SB and CBa in the paper writing. Each author read and corrected the paper. All authors read and approved the final manuscript.

\section{Acknowledgements}

We thank Julien Cohen for help with statistical analysis.

\section{Author details}

${ }^{1}$ Aix-Marseille University, APHM, Hôpital de la Conception, Centre de néphrologie et transplantation rénale, Marseille 13005, France. ${ }^{2}$ Aix-Marseille University, APHM, Hôpital de la Conception, Service d'accueil des urgences, Marseille 13005, France. ${ }^{3}$ Aix-Marseille University, APHM, Hôpital de la Conception, Laboratoire de Biochimie, Marseille 13005, France. ${ }^{4}$ Aix-Marseille University, Laboratoire de Santé Publique EA3279, Marseille 13284, France.

Received: 27 August 2013 Accepted: 10 February 2014

Published: 21 February 2014

\section{References}

1. Arampatzis S, Exadaktylos A, Buhl D, Zimmermann H, Lindner G: Dysnatraemias in the emergency room: Undetected, untreated, unknown? Wien Klin Wochenschr 2012, 124(5-6):181-183.

2. Arampatzis S, Frauchiger B, Fiedler GM, Leichtle AB, Buhl D, Schwarz C, Funk GC, Zimmermann $\mathrm{H}$, Exadaktylos AK, Lindner G: Characteristics, symptoms, and outcome of severe dysnatremias present on hospital admission. Am J Med 2012, 125(11):1125.

3. Adrogue HJ, Madias NE: Primary care: hypernatremia. N Engl J Med 2000, 342(20):1493-1499.

4. Fall PJ: Hyponatraemia and Hypernatremia (a systemic approach to causes and their correction). Postgrad Med 2000, 107(5):75-82.

5. Oufella H, Offenstadt G: Troubles de l'équilibre acido-basique et désordres hydro-électrolytiques. La revue du praticien 2003, 53:883-892.

6. Tareen N, Martins D, Nagami G, Levine B, Norris KC: Sodium disorders in the elderly. J Nat Med Association 2005, 97(2):217-224.

7. Robertson GL: Thirst and vasopressin function in normal and disordered states of water balance. J Lab Clin Med 1983, 101(3):351-369.

8. Lindner G, Funk GC: Hypernatremia in critically ill patients. J Crit Care 2013, 28(2):216.e11-20.

9. Adrogue HJ, Madias NE: Aiding fluids prescription for the dysnatrémies. Intensive Care Med 1997, 23:309-316.

10. Halperin LM, Cherney DZI, Adrogue HJ, Madias NE: Hypernatremia. N Engl J Med 2000, 343(11):817-818.

11. Lindner G, Schwarz C, Kneidinger N, Kramer L, Oberbauer R, Druml W: Can we really predict the change in serum sodium levels? An analysis of currently proposed formulae in hypernatraemic patients. Nephrol Dial Transplant 2008, 23(11):3501-3508.

12. Barsoum NR, Levine BS: Current prescriptions for the correction of hyponatremia and hypernatremia: are they too simple? Nephrol Dial Transplant 2002, 17:1176-1180.

13. Snyder NA, Feigal DW, Arieff Al: Hypernatremia in elderly patients: a heterogeneous, morbid, and iatrogenic entity. Ann Intern Med 1987, 107:309-319.

14. Palevsky PM, Bhagrath $R$, Greenberg A: Hypernatremia in hospitalized patients. Ann Inter Med 1996, 124:197-203.

15. Funk GC, Lindner G, Druml W, Metnitz B, Schwarz C, Bauer P, Metnitz PG: Incidence and prognosis of dysnatremias present on ICU admission. Intensive Care Med 2010, 36(2):304-311.

16. Stelfox HT, Ahmed SB, Khandwala F, Zygun D, Shahpori R, Laupland K. The epidemiology of intensive care unit-acquired hyponatraemia and hypernatraemia in medical-surgical intensive care units. Crit Care 2008, 12(6):R162. doi:10.1186/cc7162.
17. Levey AS, Bosch JP, Breyer Lewis J, Greene T, Rogers N, Roth D: A more accurate method to estimate glomerular filtration rate from serum creatinine: a new prediction equation. Ann Intern Med 1999, 130:461-470.

18. Liamis G, Tsimihodimos V, Doumas M, Spyrou A, Bairaktari E, Elisaf M: Clinical and laboratory characteristics of hypernatremia in an internal medicine clinic. Nephro Dial Transplant 2008, 23:136-143.

19. Chassagne P, Druesne L, Capet C, Ménard JF, Bercoff E: Clinical presentation of hypernatremia in elderly patients: a case control study. J Am Geriatr Soc 2006, 54(8):1225-1230.

20. Hausfater P, Mégarbane B, Fabricatore L, Dautheville S, Patzak A, Andronikof M, Santin A, Kierzek G, Doumenc B, Leroy C, Manamani J, Peviriéri F, Riou B: Serum sodium abnormalities during nonexertional heatstroke: incidence and prognostic values. Am J Emerg Med 2012, 30(5):741-748.

21. Al-Absi A, Gosmanova EO, Wall BM: A clinical approach to the treatment of chronic hypernatremia. Am J Kidney Dis 2012, 60(6):1032-1038.

22. Himmelstein DU, Jones AA, Woolhandler S: Hypernatremic dehydration in nursing home patients: an indicator of neglect. J Am Geriatr Soc 1983, 31(8):466-471.

23. Davis RE, Rossier CE, Enfield KB: The impact of weather on influenza and pneumonia mortality in New York City, 1975-2002: a retrospective study. PLoS One 2012, 7(3):e34091.

24. Lindner G, Funk GC, Schwarz C, Kneidinger N, Kaider A, Schneeweiss B, Kramer L, Druml W: Hypernatremia in the critically ill is an independent risk factor for mortality. Am J Kidney Dis 2007, 50(6):952-957.

25. Ayus JC, Achinger SG, Arieff A: Brain cell volume regulation in hyponatremia: role of sex, age, vasopressin, and hypoxia. Am J Physiol Renal Physiol 2008, 295(3):F619-F624.

doi:10.1186/1471-2369-15-37

Cite this article as: Bataille et al:: Undercorrection of hypernatremia is frequent and associated with mortality. BMC Nephrology 2014 15:37.

\section{Submit your next manuscript to BioMed Central and take full advantage of:}

- Convenient online submission

- Thorough peer review

- No space constraints or color figure charges

- Immediate publication on acceptance

- Inclusion in PubMed, CAS, Scopus and Google Scholar

- Research which is freely available for redistribution

Submit your manuscript at www.biomedcentral.com/submit
C Biomed Central 